\title{
Preoperative HE4 Tumor Marker and Prognostic Factors in Endometrial Cancer: Review Article
}

\author{
A. Espiau Romera*, L. Baquedano Mainar, M.J. Puente Luján, R. Laborda Gotor, \\ L. Ruiz Campo and M.A. Ruiz Conde
}

Department of Gynecology, Miguel Servet University Hospital, Zaragoza, Spain

\begin{abstract}
Purpose of the Review: The aim of the review is to summarize the current evidence of HE4 tumor marker as a prognostic marker of endometrial cancer since it is a novel and not yet validated marker in the management of this neoplasm.

Recent Findings: HE4 has been studied as a preoperative prognosis marker and the result is encouraging as it is statistically related to unfavorable prognostic markers in endometrial cancer. Having a preoperative marker that relates with prognosis is a non invasive and cost-effective way to classify the patients before the surgery act.

Summary: Clinicians could use HE4 as a prognostic marker to help them in the preoperative decision-making process. Thus, good prognostic patients with a low serum HE4 could have a less invasive surgery avoiding lymphadecnectomy which decrease the morbidity of the procedure and reducing the operative time.
\end{abstract}

Keywords: Endometrial Neoplasms, HE4, Lymphatic Metastasis.

\section{INTRODUCTION}

Endometrial cancer (EC) had an incidence of 380000 cases in 2018 [1] becoming the sixth cause of cancer in women in developed countries and the $2 \%$ of cancer deaths in woman [2].

Nowadays, no serum tumor marker is validated in the study of EC, although some studies point HE4 (human epididymis protein 4) as a useful tool in this kind of cancer.

Evidence that connects HE4 preoperative levels with prognostics factors of EC is still restricted and generates heterogeneous findings. Nevertheless, it seems like HE4 preoperative value can be correlated with prognostic variables of EC [3-7].

A tumor marker which can predict poor prognostic factors in a preoperative time would be useful in order to plan a more personalized surgery act.

\section{PROGNOSTIC FACTORS IN ENDOMETRIAL CANCER}

Most cases of EC have good prognosis as they are usually diagnosed in early FIGO (Fédération Internationale de Gynécologie et d'Obstétrique) stage $(80 \%$ in stage I). The survival rate in 5 years is about $80-85 \%$ [8] which decrease if metastasis or regional spreading appear (5 years survival of 68 and $17 \%$ respectively) [9].

*Address correspondence to this author at the Department of Gynecology, Miguel Servet Universitary Hospital, Paseo Isabel La Católica 1-3, 50009, Zaragoza, Spain; Tel: +34 654963535; E-mail: andreaespiau@gmail.com
The most important poor prognosis factors in EC consist in [8] lymphatic node involvement, advanced FIGO stage (III-IV), myometrial invasion $>50 \%$, high histological tumor grade (G3) and non-endometrioid histological subtype.

Presenting lymphatic metastasis is a negative prognostic factor, regardless of the FIGO stage, because it represents a potentially focus of disease recurrence [10].

Other bad prognosis factors are: age over 60 years, lymph-vascular space invasion (LVSI), tumor size over $2 \mathrm{~cm}$, uterine isthmus or cervical involvement or extrauterine spreading [8].

Randomized studies had observed that patients aged over 60 years had a higher relapse risk even in early stages. This finding is relevant in order to individualize the adjuvant therapy [8].

The LVSI seems to be a predictor of lymphatic spreading, poor prognosis and high risk of recurrence. Its presence could implicate a change in the management of the patient even in early stage cases, and the requirement of doing a lymphadenectomy (LDN) and adjuvant therapy [11].

\section{TUMOR MARKERS IN ENDOMETRIAL CANCER}

At present time no tumor marker is validated for being used in the management of patients with EC. Several markers have been studied with unsatisfying results: chaperonin 10, CA 125, CA 15.3, CA19.9, CA 72.4, CEA, OVX1 and M-CSF [12]. 
The ESMO-ESGO-ESTRO Consensus Conference on Endometrial Cancer in 2016 affirmed that there is evidence that the serum tumor markers cancer antigen 125 (CA-125) and, more recently, human epididymis protein 4 , are significantly correlated with histological grade, FIGO stage, lymph node metastasis, myometrial invasion and cervical involvement. However, the appropriate cut-off has not been established and evidence that serum marker assessment is clinically useful is lacking. In this consensus, the authors concluded that there is no evidence for the clinical usefulness of serum tumor markers, including CA-125 and HE4 level in EC [9].

\section{HE4}

HE4 is a $25 \mathrm{kDa}$ protein secreted in distal part of epididymis which was discovered in 1991 by Kirchhoff et al. [3]. High HE4 levels can be detected in vas deferens, salivary glands, respiratory system, mammary tissue and female genital tract [13].

It is an endogenous protease inhibitor detectable in the circulation, as it is a member of the whey-acidicprotein four-disulfide core domain family [13]. This protein is codified by the WFDC2 gen located in chromosome 20q12.

Schummer (1991) discovered that HE4 gen is overexpressed in ovarian cancer and, recently, it has been found out that HE4 plays a role on regulation and growth of ovarian and endometrial tumors [13]. Overexpression of HE4 promote cell migration and adhesion while suppression of HE4 decrease tumor growth [14].

Nevertheless, these potential applications are still been studied and the current evidence is limited and heterogeneous. What is more, it is necessary to develop some studies to standardize the normal levels of HE4 in healthy people in every fluid [13].

Nowadays, this marker is used in ovarian cancer as it is found out that HE4 is more accurate than CA 125 for distinguish benign and neoplasm lesions. HE4 is accepted for the management of ovarian cancer, as FDA approved in 2009 the ROMA algorithm [15].

HE4 serum value can be disrupted by some factors like renal function, patient age, smoking habit and coexistence of certain tumors, as it has been told [13]. Thus, the normal ranges of this marker need to be defined among women of different ages, abnormal renal function and smoking habit [10].
USE OF HE4 AS A PROGNOSTIC MARKER IN ENDOMETRIAL CANCER

A review of the literature was made to analyze the potential association with HE4 as a preoperative marker and some of the most important prognostic factors in EC.

A significant correlation between advanced stage disease (III-IV) and higher HE4 levels was showed in several studies $[4,5,10,16-23]$, when analyzing the FIGO stage.

Although there is little evidence to find a lineal correlation between HE4 serum marker and the FIGO stages, Abdalla el al. (2016) [24] found a significant rise of HE4 in patients with stage III-IV vs I-II, IB vs IA, II-III vs I, IB to IIIC vs IA and IIIC vs IA to IIIB.

On the other hand, some studies do not found significant differences in the tumor stage $[4,21]$.

Deep myometrial invasion is strongly associated with lymphatic metastasis. Thus, in the international guides of EC management, the presence of deep myometrial invasion (IB stage) lead to the requirement of doing a LDN in apparently low risk cases [8]. In the review of the literature, the deep myometrial invasion was related to higher values of preoperative HE4 [4, 10, 16-21].

A statistically significant difference of HE4 level was found between G1 FIGO grade tumors and G2-G3 ones, which have a higher value of preoperative HE4 $[5,10,17,18,20,22,23]$. However, some of the studies did not find this difference [16, 19, 24, 25].

Most authors do not specify the histological type of EC (endometrioid vs non-endometrioid). When this distinction is made, the majority of the studies reveal a higher HE4 preoperative value in non-endometrioid types $[6,16,17,19,20,24,26]$, although the differences are no statistically significant. Two of the reviewed articles find statistically significant differences between the HE4 level and the EC subtype, however, the results are inconsistent $[18,27]$.

The PORTEC 1- 2 trials [11] pointed LVSI as a risk factor for regional nodal recurrence and for distant metastasis as has been said previously. Evidence in the correlation of HE4 and LVSI is still limited with a reduced number of studies that refer to the relationship between HE4 and LVSI [16, 19, 26], showing all of them a significant rise of HE4 in patients who present LVSI. 
When analyzing the lymphatic metastasis, some studies find no statistically significant difference between HE4 value lymph node involvement [18, 19, $21,24,25]$, while other showed a statistically significant level of HE4 in the preoperative test if lymphatic involvement was present $[10,16,17,26]$. Wang et al. (2017) [10] in a broad and significant study of 258 patients, studied the predictive values of HE4 in the detection of lymph node metastasis and obtained a sensitivity (SEN) of $82.4 \%$, specificity (SPE) of $52.3 \%$, which reflects a useful preoperative tool in the study of node involvement.

A recent study of $\mathrm{Li}$ et al. (2019) [7] shows the relationship between risk factors of EC and lymphatic node involvement. They studied 6 risk factors in EC (serum CA $125>27.6 \mathrm{U} / \mathrm{mL}$, serum HE4 > $132 \mathrm{pmol} / \mathrm{L}$, non endometrioid histology, myometrial invasion $>50$ $\%$, positive peritoneal cytology and LVSI). All of them were independent risk factors for pelvic node affectation. The incidence of pelvic metastasis was $0.0 \%$ in the absence of the above 6 factors, while the incidence was $100 \%$ in the presence of more than four risk factors. The authors concluded that when none of these independent risk factors was present, patients without pelvic metastasis can be screened out and LDN could be not recommended.

These study shows that preoperative serum HE4 was one of the independent risk factors for pelvic involvement in EC patients, being the risk of pelvic metastasis in patients who have HE4 $\geq 132 \mathrm{pmol} / \mathrm{L}$ 4.25 times compared to patients with HE4 $<132$ $\mathrm{pmol} / \mathrm{L}$.

\section{CONCLUSION}

HE4, a novel preoperative serum marker, seems to be useful to manage EC and is related to the most important prognostic factors in EC (deep myometrial invasion, FIGO advanced stage, lymphatic involvement and FIGO tumor grade, among others).

A blood analysis could help clinicians to personalize the EC surgery using the serum HE4 as a preoperative prognostic marker, together with other already accepted diagnostic tools.

Further prospective studies are needed to validate HE4 as a preoperative prognostic tool and to apply this marker in the regular clinical practice.

\section{REFERENCES}

[1] Bray F, Ferlay J, Soerjomataram I, Siegel RL, Torre LA, Jemal A.Global cancer statistics 2018: GLOBOCAN estimates of incidence and mortality worldwide for 36 cancers in 185 countries. CA: A Cancer Journal for Clinicians 2018; 68(6): 394-424.

https://doi.org/10.3322/caac.21492

[2] Felix AS, Yang HP, Bell DW, Sherman ME. Epidemiology of Endometrial Carcinoma: Etiologic Importance of Hormonal and Metabolic Influences. Advances in Experimental Medicine and Biology 2017; 3-46.

https://doi.org/10.1007/978-3-319-43139-0_1

[3] Huang G-Q, Xi Y-Y, Zhang C-J, Jiang X. Serum Human Epididymis Protein 4 Combined with Carbohydrate Antigen 125 for Endometrial Carcinoma Diagnosis: A Meta-Analysis and Systematic Review. Genetic Testing and Molecular Biomarkers 2019; 23(8): 580-8. https://doi.org/10.1089/gtmb.2019.0046

[4] PresI J, Ovesna P, Novotny Z, Vlasak P, Bouda J, Kostun JAN. Importance of Preoperative Knowledge of the Biomarker HE4 in Early-stage Endometrial Cancer Regarding Surgical Management. Anticancer Research 2017; 37(5): 2697-702.

https://doi.org/10.21873/anticanres.11619

[5] Stiekema A, Lok C, Korse CM, van Driel WJ, van der Noort V, Kenter GG. Serum HE4 is correlated to prognostic factors and survival in patients with endometrial cancer. Virchows Arch 2017; 470(6): 655-64 https://doi.org/10.1007/s00428-017-2115-1

[6] Benati M, Montagnana M, Danese E, Paviati E, Giudici S Ruzzenente O. The clinical significance of DJ-1 and HE4 in patients with endometrial cancer. Journal of Clinical Laboratory Analysis 2018; 32(1): 1-5. https://doi.org/10.1002/jcla.22223

[7] Li Y, Cong P, Wang P, Peng C, Liu M, Sun G. Risk factors for pelvic lymph node metastasis in endometrial cancer. Archives of Gynecology and Obstetrics 2019; 300(4): 100713.

https://doi.org/10.1007/s00404-019-05276-9

[8] "Oncoguía SEGO: Cáncer de Endometrio. Guía De Práctica Clínica en Cáncer Ginecológico y Mamario. Progresos en Obstetricia y Ginecología 2016; 60(3): 274-302.

[9] Colombo N, Creutzberg C, Amant F, Bosse T, GonzálezMartín A, Ledermann J. ESMO-ESGO-ESTRO consensus conference on endometrial cancer: Diagnosis, treatment and follow-up. Radiotherapy and Oncology 2015; 117(3): 559-81. https://doi.org/10.1016/j.radonc.2015.11.013

[10] Wang Y, Han C, Teng F, Bai Z, Tian W, Xue F. Predictive value of serum HE4 and CA125 concentrations for lymphatic metastasis of endometrial cancer. International Journal of Gynecology \& Obstetrics 2017; 136(1): 58-63. https://doi.org/10.1002/ijgo.12010

[11] Bosse T, Peters EEM, Creutzberg CL, Jürgenliemk-Schulz IM, Jobsen JJ, Mens JWM. Substantial lymph-vascular space invasion (LVSI) is a significant risk factor for recurrence in endometrial cancer - A pooled analysis of PORTEC 1 and 2 trials. European Journal of Cancer 2015; 51(13): 1742-50. https://doi.org/10.1016/j.ejca.2015.05.015

[12] Capriglione S, Plotti F, Miranda A, Lopez S, Scaletta G Moncelli $M$. Further insight into prognostic factors in endometrial cancer: the new serum biomarker HE4. Expert Review of Anticancer Therapy 2017; 17(1): 9-18 https://doi.org/10.1080/14737140.2017.1266263

[13] Qu W, Gao Q, Chen H, Tang Z, Zhu X, Jiang S-W. HE4-test of urine and body fluids for diagnosis of gynecologic cancer. Expert Review of Molecular Diagnostics 2017; 17(3): 239-44. https://doi.org/10.1080/14737159.2017.1282824 
[14] Li L, Zhu Y, Zhong Y, Su T, Fan X, Xi Q. Human epididymis protein 4 in endometrial cancer: A meta-analysis. Clinica Chimica Acta 2018; 482: 215-23 https://doi.org/10.1016/j.cca.2018.03.040

[15] Gorp T Van, Cadron I, Despierre E, Daemen A, Leunen K, Amant F. HE4 and CA125 as a diagnostic test in ovarian cancer: prospective validation of the Risk of Ovarian Malignancy Algorithm. British Journal of Cancer 2011; 104: 863-70.

https://doi.org/10.1038/sj.bjc.6606092

[16] Abbink K, Zusterzeel PL, Geurts-Moespot AJ, Herwaarden AE van, Pijnenborg JM, Sweep FC. HE4 is superior to CA125 in the detection of recurrent disease in high-risk endometrial cancer patients. Tumor Biology 2018; 40(2): 110.

https://doi.org/10.1177/1010428318757103

[17] Zanotti L, Bignotti E, Calza S, Bandiera E, Ruggeri G, Galli C. Human epididymis protein 4 as a serum marker for diagnosis of endometrial carcinoma and prediction of clinical outcome. Clinical Chemistry and Laboratory Medicine 2012; 50(12): 2189-98. https://doi.org/10.1515/cclm-2011-0757

[18] Capriglione S, Plotti F, Miranda A, Ricciardi R, Scaletta G, Aloisi A. Utility of tumor marker HE4 as prognostic factor in endometrial cancer: a single-center controlled study. Tumor Biology 2015; 36(6): 4151-6. https://doi.org/10.1007/s13277-015-3049-3

[19] Angioli R, Plotti F, Capriglione S, Montera R, Damiani P, Ricciardi R. The role of novel biomarker HE4 in endometrial cancer: a case control prospective study. Tumor Biology 2013; 34(1): 571-6. https://doi.org/10.1007/s13277-012-0583-0

[20] Omer B, Genc S, Takmaz O, Dirican A, Kusku-Kiraz Z, Berkman $S$. The diagnostic role of human epididymis protein 4 and serum amyloid-A in early-stage endometrial cancer patients. Tumour Bioloy 2013; 34(5): 2645-50. https://doi.org/10.1007/s13277-013-0814-z
[21] Bignotti E, Ragnoli M, Zanotti L, Calza S, Falchetti M, Lonardi $\mathrm{S}$. Diagnostic and prognostic impact of serum HE4 detection in endometrial carcinoma patients. British Journal of Cancer 2011; 104(9): 1418-25.

https://doi.org/10.1038/bjc.2011.109

[22] Saarelainen SK, Peltonen N, Lehtimäki T, Perheentupa A, Vuento MH, Mäenpää JU. Predictive value of serum human epididymis protein 4 and cancer antigen 125 concentrations in endometrial carcinoma. American Journal of Obstetrics \& Gynecology 2013; 209(2): 142.e1-142.e6. https://doi.org/10.1016/j.ajog.2013.04.014

[23] Kalogera E, Scholler N, Powless C, Weaver A, Drapkin R, Li J. Correlation of serum HE4 with tumor size and myometrial invasion in endometrial cancer. Gynecologic Oncology 2012; 124(2): 270-5. https://doi.org/10.1016/j.ygyno.2011.10.025

[24] Abdalla N, Piórkowski R, Stanirowski P, Słomka A, Cendrowski K, Sawicki W. Assessment of levels of the tumor markers HE4 and CA125 considering staging, grading and histological types of endometrial cancer. Menopause Review 2016; 15(3): 133-7. https://doi.org/10.5114/pm.2016.63059

[25] Moore RG, Miller CM, Brown AK, Robison K, Steinhoff M, Lambert-Messerlian G. Utility of Tumor Marker HE4 to predict depth of myometrial invasion in endometrioid adenocarcinoma of the uterus. International Journal of Gynecological Cancer 2011; 21(7): 1185-90. https://doi.org/10.1097/IGC.0b013e3182229ad8

[26] Mutz-Dehbalaie I, Egle D, Fessler S, Hubalek M, Fiegl H Marth C. HE4 is an independent prognostic marker in endometrial cancer patients. Gynecologic Oncology 2012; 126(2): 186-91. https://doi.org/10.1016/j.ygyno.2012.04.022

[27] Moore RG, Brown AK, Miller MC, Badgwell D, Lu Z, Allard WJ. Utility of a novel serum tumor biomarker HE4 in patients with endometrioid adenocarcinoma of the uterus. Gynecologic Oncology 2008; 110(2): 196-201. https://doi.org/10.1016/j.ygyno.2008.04.002

Received on 25-10-2019 Accepted on 12-11-2019

Published on 25-11-2019

https://doi.org/10.30683/1927-7229.2019.08.06

(C) 2019 Romera et al.; Licensee Neoplasia Research.

This is an open access article licensed under the terms of the Creative Commons Attribution Non-Commercial License (http://creativecommons.org/licenses/by-nc/3.0/) which permits unrestricted, non-commercial use, distribution and reproduction in any medium, provided the work is properly cited. 